\title{
Obituary: A Remembrance of D. Kay Clawson MD (1927-2016)
}

\section{Roger O. Lambson PhD}

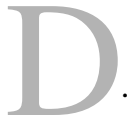

Kay Clawson MD, former President of The Association of Bone and Joint Surgeons ${ }^{\circledR}$, passed away on March 11 , 2016 while on vacation in California. He was 88 years old.

Dr. Clawson (Fig. 1) is widely recognized for his modification of a sliding hip screw, which would eventually become the standard treatment of intertrochanteric hip fractures [1]. $\mathrm{He}$ also introduced to the United States the concept of closed nailing with intramedullary reaming for treating femoral shaft fractures [2]. These advances facilitated patient recovery, and established Dr. Clawson as a leader in the field.

The author certifies that his, or any members of his immediate family, has no commercial associations (eg, consultancies, stock ownership, equity interest, patent/licensing arrangements, etc) that might pose a conflict of interest in connection with the submitted article.

The opinions expressed are those of the writers, and do not reflect the opinion or policy of $C O R R^{\mathbb{R}}$ or The Association of Bone and Joint Surgeons ${ }^{\circledR}$.

R. O. Lambson PhD ( $\square)$

University of Kansas Medical Center,

3901 Rainbow Blvd., Kansas City,

KS 66160, USA

e-mail: rlambson39@gmail.com

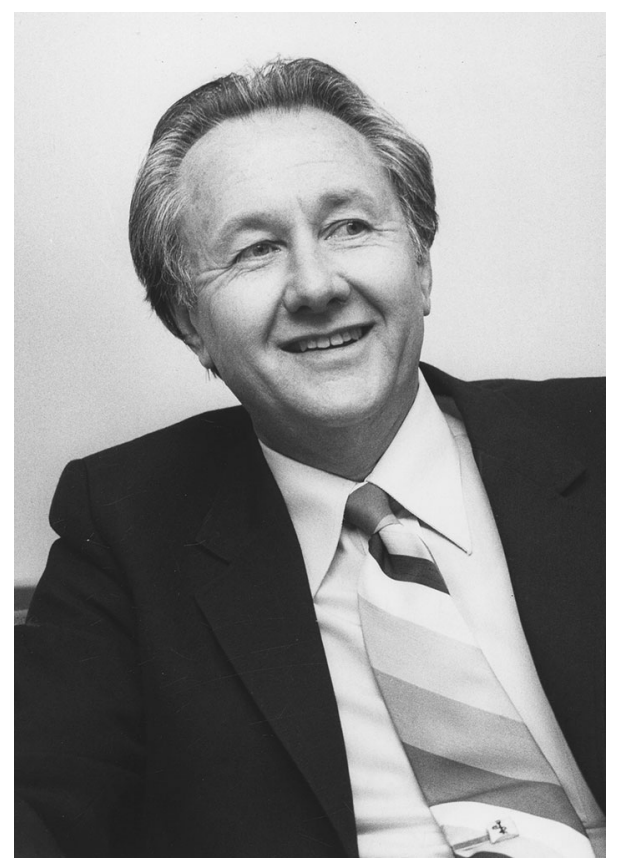

Fig. 1 During his tenure as Dean of the University of Kentucky College of Medicine, Dr. Clawson helped raise funds for additions to the Chandler Medical Center and the School of Medicine. (Published with permission from the University of Kentucky Special Collections Research Center).

A Salt Lake City native, Dr. Clawson completed medical school at Harvard University, and his orthopaedic residency at Stanford University. He joined the University of Washington in 1958, and in 1965, he became the founding Chairman of the Department of Orthopaedic Surgery at the school, a position he held for 10 years.
In 1975, Dr. Clawson moved to the University of Kentucky to serve as Dean of the College of Medicine. At that time, I was on sabbatical leave as the Associate Dean for Student Affairs and played no role in his recruitment or orientation to that institution. While "serving at the pleasure of" this new Dean was of some concern, over the 
course of 20 years working with him there and at the University of Kansas, I soon found out about and appreciated Dr. Clawson's leadership and administrative style—as did all of our faculty.

“During Dr. Clawson's tenure, his leadership was evident not only in recognizing talent but providing resources to implement and support programs," H. Thomas Weigert MD, Emeritus Professor and Chair of the Department of Family Practice and former colleague of Dr. Clawson's at the University of Kentucky, told $\operatorname{CORR}^{\circledR}$. "He intuitively mentored faculty and chairs to expand individual responsibility, horizons, and growth for leadership positions. He implemented an evaluation process for programs, chairs, and faculty, which streamlined decisions and made the most of resources available. His management style was 'open door,' respectively seeking ideas and open to opinions that were different from his."

Coming to this new Kentucky medical school with outstanding Harvard and Stanford academic credentials, and having established and built an outstanding Department of Orthopedic Surgery at the University of Washington, Dr. Weigert commented that Dr. Clawson quickly demonstrated his deep knowledge and understanding of academic medicine, and used that understanding to guide those in his charge.

$\mathrm{He}$ was extremely well read regarding the serious and evolving issues facing medical education, the qualifications of its students, and the changes needed to attract and prepare them for effective medical practices. His sensitivity to the need to attract more women, minorities, and those from underserved areas was acute, and these insights and values were manifest throughout his working and retirement years.

A founding member of both the American Orthopedic Society for Sports Medicine and the Association of Orthopedic Chairmen, Dr. Clawson served leadership roles in myriad orthopaedic, academic, and organized medicine organizations. His participation and presentations at national meetings increased his visibility and further honed his perspective. He wrote prolifically, and he thoroughly relished his role at the head of the table or behind the podium. He was energetic and moved quickly. As was noted at his retirement, he was a visionary leader who was always out front. In fact, he was often so far out in front that those providing supporting roles could easily lose sight of his next vision.

As a strong leader, he often used both influential national and local contacts to provide linkages to the financial and political resources needed to realize his vision. During his tenure as Dean of the University of Kentucky College of Medicine, Dr. Clawson helped raise funds for additions to the Chandler Medical Center and the School of Medicine. Because of his tireless efforts, University of Kentucky officials renamed a wing of the Kentucky Clinic, which was the primary UK HealthCare outpatient clinic, the "D. Kay Clawson Pavilion." The ceremony took place on his $75^{\text {th }}$ birthday [3].

Dr. Clawson continually evaluated the knowledge, skills, and effectiveness of those on his management team and identified areas of need. If the organizational structure needed an infusion of experience, he often shuffled roles and responsibilities or recruited nationally to meet those needs. In the course of a 20-year academic relationship, he provided me six different leadership roles, all growth opportunities.

Dr. Clawson and his wife Jan did not ignore the social side of leadership. They opened their homes to students, faculty, staff, peers, and visitors in a warm, sharing, and hospitable manner. They also were masters in providing opportunity for personal growth and development. Over and over again, Dr. Clawson would identify, recruit, and present unstructured opportunities to young, 


\section{Obituary}

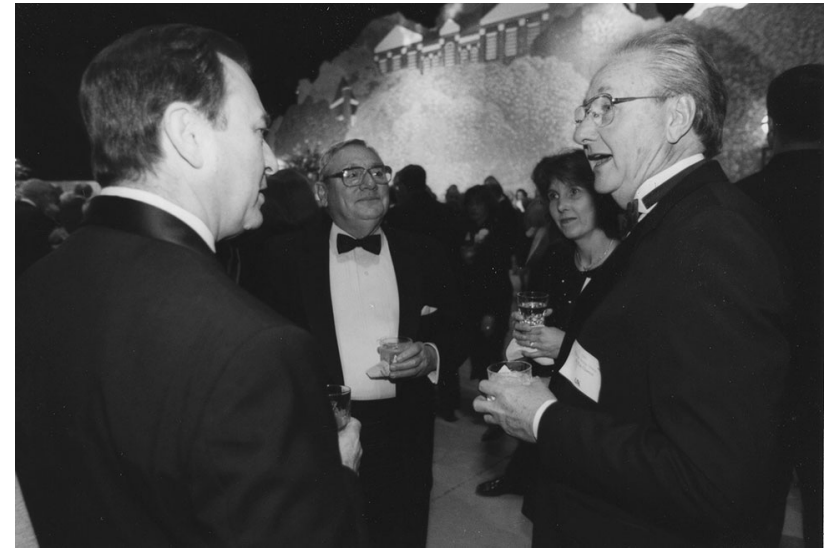

Fig. 2 Dr. Clawson's gregarious, often outspoken, bigger-than-life personality was usually effective in presenting his vision. Here, he is holding court at a fellows dinner in 1992. From left to right: University of Kentucky President Charles T. Wethington, Jr, University of Kentucky alumnus Warren Rosenthal, Dr. Clawson's daughter, Dr. Kim Clawson Rosenstein, and Dr. Clawson. (Published with permission from the University of Kentucky Special Collections Research Center).

unproven professionals. His gregarious, often outspoken, bigger-thanlife personality (Fig. 2) was usually effective in presenting his vision, but he subsequently nourished the execution of that task with little intervention or management; outcomes were most important.
Dr. Clawson was a productive and respected leader at all stages of his professional career. His perpetual and voracious reading and close monitoring of trends in education, research, and medical care as well as the financing of these endeavors not only set a good example, but also a strong incentive to follow and to try to give back as he gave to us. He will be sorely missed.

\section{References}

1. Clawson DK. Trochanteric fractures treated by the sliding screw plate fixation method. J Trauma. 1964;4: 737-752.

2. Clawson DK, Smith RF, Hansen ST. Closed intramedullary nailing of the femur. J Bone Joint Surg Am. 1971;53:681-692.

3. Gay TJ. Building wing named after former dean. Available at: http:// www.uky.edu/PR/News/Archives/2002/ Aug2002/clawsonwing.htm. Accessed July 15, 2016. 